\title{
Building a Science of Partnership-Focused Research: Forging and Sustaining Partnerships to Support Child Mental Health Prevention and Services Research
}

\author{
Catherine P. Bradshaw $•$ Katherine Taylor Haynes
}

Published online: 14 June 2012

(C) Springer Science+Business Media, LLC 2012

\begin{abstract}
Building on growing interest in translational research, this paper provides an overview of a special issue of Administration and Policy in Mental Health and Mental Health Service Research, which is focused on the process of forging and sustaining partnerships to support child mental health prevention and services research. We propose that partnership-focused research is a subdiscipline of translational research which requires additional research to better refine the theoretical framework and the core principles that will guide future research and training efforts. We summarize some of the major themes across the eight original articles and three commentaries included in the special issue. By advancing the science of partnershipfocused research we will be able to bridge the gap between child mental health prevention and services research and practice.
\end{abstract}

Keywords Partnerships - Translational research . Community-based participatory research - Prevention . Services · Child mental health

C. P. Bradshaw $(\bowtie)$

Department of Mental Health, Johns Hopkins Center for the Prevention of Youth Violence, Johns Hopkins Center for Prevention and Early Intervention, Johns Hopkins Bloomberg School of Public Health, 624 N. Broadway, Room 839,

Baltimore, MD 21205, USA

e-mail: cbradsha@jhsph.edu

\section{K. T. Haynes}

Department of Leadership, Policy and Organizations, Peabody

College, National Center for Scaling Up Effective Schools,

Vanderbilt University, Nashville, TN 37203-5721, USA

e-mail: katherine.taylor.haynes@vanderbilt.edu
There is growing interest in the intersection of research and practice across multiple disciplines. This field, generally referred to as translational research (Woolf 2008), has become a priority among policy makers, practitioners, researchers, and educators. While much attention has been focused on the importance of translational research, particularly in the area of children's behavioral and mental health (O'Connell et al. 2009), there has been relatively limited work aimed at understanding and describing the role that partnerships play in the translation process. Such partnerships are critical, if not essential, to the effective and efficient translation of research findings to practice and policy; however, additional investigation is needed into the partnerships that serve as a context and a guide for the work.

In an effort to advance the science of partnershipfocused research, this special issue of Administration and Policy in Mental Health and Mental Health Service Research includes a collection of original research-based articles and invited commentaries on the process of forging and sustaining partnerships to support child mental health prevention and services research. Although the current issue focuses on the substantive area of child mental health prevention and services research, we believe that many of the lessons learned from these studies can inform work in other areas, such as health and education, and for other populations.

The overall goals of the special issue were to (1) share information about how to develop and maintain practice relationships to support child mental health services and prevention research; (2) identify theoretical or conceptual models which guide the formation and maintenance of research partnerships; and (3) identify future research directions related to practice relationships. We are pleased to include eight original studies from several leading 
scholars in the fields of child mental health prevention and services research. We also have included expert commentaries from a leading prevention and services researcher, and two federal agencies, the National Institute of Mental Health (NIMH) and the National Institute on Drug Abuse (NIDA), which have had a significant impact on translational research more broadly, and have a growing interest in partnership-focused research.

\section{Overview of the Special Issue}

The first paper is by Bradshaw et al. (2012), and it summarizes a program of school-based prevention research which blends the public health perspective and an organizationally-focused educational framework to prevent behavioral and mental health problems in children and adolescents. They provide several examples of their collaborative research efforts that have leveraged federal grants to support large-scale randomized controlled trials; this work has also informed the scale-up of the prevention model in over half of the public schools in Maryland. The paper by Short et al. (2012) also focuses on schools, but with a keen interest in the role that partnerships play in narrowing the gap between research and practice. They describe the ROPE (Relevant research, Organizational capacity, Platforms for knowledge exchange, and Evaluation support) model for fostering collaborative research-practice partnerships across countries, organizations, sectors, and disciplines in order to increase the uptake of evidence-based practices in schools.

Riemer et al. (2012) describes some of the critical components of successful collaboration which supported the development and implementation of a measurement feedback system in one of the largest behavioral health service providers in the U.S. They highlight the importance of environmental characteristics, structural characteristics, and group dynamics in creating effective partnerships. The paper by Poduska et al. (2012) describes the development of a partnership with the Houston Independent School District and the greater Houston community to support research and program sustainability. They provide an overview of their conceptual framework which guided their partnership and base-building activities. They also summarize the six-step process used to launch the successful school-based research partnership in Houston.

Shifting to another context for the delivery of children's mental health prevention programming, Bumbarger and Campbell (2012) describe a decade-long partnership between the Prevention Research Center at Penn State and the Pennsylvania Commission on Crime and Delinquency which has supported the implementation of approximately
200 replications of evidence-based prevention and intervention programs. They apply a Type 2 translational research framework and report findings from a series of studies indicating a significant and sustained impact of these prevention programs on youth outcomes.

Also focusing on implementation of programs across multiple agencies, the paper by Chamberlain et al. (2012) summarizes three models of research-practice collaboration to scale-up evidence-based practices in child welfare, juvenile justice, and the mental health system in the U.S. and England. Their collaborative research efforts have resulted in randomized controlled trials testing the effectiveness of the models. They highlight the importance of contextual factors in forming and sustaining effective research partnerships. Sandler et al. (2012) describe an ongoing collaboration between prevention researchers and the Maricopa Domestic Relations Court focused on parental divorce and separation. The collaborative partnership has conducted multiple research projects over the course of nearly three decades, including a randomized trial of an intervention that targeted children whose parents are divorcing.

The paper by Brown et al. (2012) summarizes some of the impressive work of the Prevention Science Methodology Group (PSMG), which serves as a model for forming close collaborations among methodologists, communities, agencies, and scientists to conduct rigorous effectiveness trials. PSMG's more recent research efforts have focused on processes that facilitate or impede quality implementation of evidence-based programs; therefore, they also summarize some novel methodologic work in implementation science related to the adoption and implementation of prevention programs.

Drawing on nearly a half century of experience developing and sustaining research-practice partnerships, Kellam (2012) outlines ten steps for developing and maintaining public support for prevention and intervention programs. His commentary identifies the public health and prevention science perspectives as helpful frameworks for forming and studying partnerships. Kellam also emphasizes the importance of training the next generation of researchers in partnership-based research. As illustrated in the other two commentaries, both NIMH (Chambers et al. 2012) and NIDA (Robertson et al. 2012) have had a tremendous impact on translational research, most notably through their funding of specific research projects, research centers, and training programs. These agencies also place great emphasis on the role of partnerships in promoting the translation of research findings to practice and policy; the authors highlight this as a critical future direction for bridging the gap between research and practice. 


\section{Common Themes}

In looking across the eight original papers and three commentaries included within this special issue, a number of common themes emerge. For example, many of the authors provide descriptions of the important role of partnerships or "practice relationships" in supporting implementation of mental health prevention programs and improved service delivery across multiple service sectors. They all highlight the importance of voice and shared decision-making in the research process (Israel et al. 2005). It was exciting to see that nearly all of the papers include community partners as coauthors. The special issue was, by design, multidisciplinary, as we wanted to highlight the multiple contexts in which practice-based research was being conducted, such as schools and school districts, juvenile justice, family courts, community-based mental health, hospitals, and other state agencies, to name a few.

Public health has historically been a field that has been more partnership focused, but we see several examples in special issue of other service sectors and fields, such as education and the courts, that serve as a context for forging long-term partnerships to prevent mental health problems and deliver mental health services to children and families. The contextual influences on partnerships are also critical to understand. Several of the papers highlight collaboration across multiple contexts, and the different role each partner plays across context and service sector. A related issue is careful consideration of the motivating factors for each research partner and how to navigate situations where the research process or the findings do not meet all partners' goals.

Several of the papers described the process, importance, and outcomes of forging partnerships between researchers and practitioners to foster high quality child mental health services and prevention research. Some of the key components or facets of successful partnerships between practitioners and researchers are identified. Several of the authors provide examples of specific strategies for fostering successful partnerships, such as spending time together in informal and unstructured settings where friendships are likely to develop and authentic personal relationships are formed. This type of networking and personal exchange also provides a venue for open and frank discussions about how to improve the partnership, the research process, and the outcomes. Although challenging to do, the papers emphasize the importance of building personal and professional relationships that are authentic and sustainable and that extend beyond any particular project or grant.

The papers also provide several examples of situations in which practitioners or service providers found it advantageous to seek out and build on existing relationships with researchers, such as to evaluate large-scale initiatives or policy relevant activities. There is often a question of the role that different partners play and which skills and resources each partner brings to the relationship. A common language and alignment of goals is important to ensure mutual understanding. Yet, it is essential that all partners get their unique, agency-specific needs meet in order for the partnership to be mutually beneficial. For example, researchers often need to publish novel findings in peer-reviewed publications, whereas practitioners may be more motivated to evaluate locally developed programs to determine their impact. There are several examples of situations provided, such as the roll out of a new prevention or service model, which afforded a unique and strategic opportunity for researchers to embed a rigorous research design (e.g., randomization). It is quite clear that the partnership efforts were most successful when they had high levels of trust and were focused on a jointly agreed upon 'program of research', rather than just a specific project. Without the preexisting partnership and foundation of trust, the rigorous research design would not have been feasible.

Each set of researchers highlighted some lessons learned from forming and sustaining partnerships. They provide some insight into the realities of the partnerships, including some of the missteps and challenges. Several of the authors disclosed some circumstances which challenged the partnership. Some of those challenges appeared to stem from issues associated with data sharing, infrastructure and capacity to conduct research, and fidelity of program implementation. The authors provide additional insights into trade secrets related to the identification of specific points of contact, as well as the importance of information technology and troubleshooting problems early in the process. Resource sharing and shared decision-making can also be challenging for traditional researchers to navigate if they have not adopted a partnership-focused approach.

Several examples of ethnographic, mixed-methods, and quality improvement research activities are described, with a particular focus on the process by which the findings are shared and used to inform the work of the partnerships. The authors drew upon several different literatures and fields of research, including Type 1 and 2 translational research (Rohrbach et al. 2006), the prevention science perspective, and related conceptual frameworks such as communitybased participatory research (Israel et al. 2005), participatory action research, or design-based research (Design-Based Research Collective 2003). Others applied systems theory, organizational theories, and social networks to their research in child mental health services and prevention programming. However, there was some variability in the extent to which theoretical models guided the formation or the work of the partnerships. In fact, the application of theory to the partnership process appears to 
be an area needing additional consideration and research. As suggested by Kellam (2012), further research is also needed to operationalize the critical elements of successful partnerships, as such efforts would enable us to actually test the extent to which the partnership resulted in improved program-level and youth-level outcomes over traditional researcher-driven approaches. We hope that these examples of successful partnerships and lessons learned will to inform the nascent science of partnershipbased research and the broader field of translational research. This work is critical for bridging the science to practice gap in children's mental health services and prevention research.

\section{References}

Bradshaw, C. P., Pas, E. T., Bloom, J., Barrett, S., Hershfeldt, P., Alexander, A., et al. (2012). A state-wide partnership to promote safe and supportive schools: The PBIS Maryland initiative. Administration and Policy in Mental Health and Mental Health Services Research. doi:10.1007/s10488-011-0384-6.

Brown, C. H., Kellam, S. G., Kaupert, S., Muthén, B. O., Wang, W., Muthén, L. K., et al. (2012). Partnerships for the design, conduct, and analysis of effectiveness, and implementation research: Experiences of the Prevention Science and Methodology Group. Administration and Policy in Mental Health and Mental Health Services Research. doi:10.1007/s10488-011-0387-3.

Bumbarger, B. K., \& Campbell, E. M. (2012). A state agencyuniversity partnership for translational research and the dissemination of evidence-based prevention and intervention. Administration and Policy in Mental Health and Mental Health Services Research. doi:10.1007/s10488-011-0372-x.

Chamberlain, P., Roberts, R., Jones, H., Marsenich, L., Sosna, T., \& Price, J. M. (2012). Three collaborative models for scaling up evidence-based practices. Administration and Policy in Mental Health and Mental Health Services Research. doi:10.1007/ s10488-011-0349-9.

Chambers, D. A., Pringle, B., \& Juliano-Bult, D. (2012). Connecting science and practice in child and adolescent mental health services research. Administration and Policy in Mental Health and Mental Health Services Research. doi:10.1007/s10488011-0399-z.

Design-Based Research Collective. (2003). Design-based research: An emerging paradigm for educational inquiry. Educational Researcher, 32(1), 5-8.
Israel, B. A., Eng, E., Schulz, A. J., \& Parker, E. A. (2005). Introduction to methods in community-based participatory research for heath. In B. A. Israel, E. Eng, A. J. Schulz, \& E. A. Parker (Eds.), Methods in community-based participatory research for health (pp. 3-29). San Francisco: Jossey-Bass.

Kellam, S. G. (2012). Developing and maintaining partnerships as the foundation of implementation and implementation science: Reflections over a half century. Administration and Policy in Mental Health and Mental Health Services Research. doi: 10.1007/s10488-011-0402-8.

O'Connell, M. E., Boat, T., \& Warner, K. E. (2009). Preventing mental, emotional, and behavioral disorders among young people: Progress and possibilities. Committee on the prevention of mental disorders and substance abuse among children, youth and young adults: Research advances and promising interventions; Institute of Medicine; National Research Council. Washington, DC: The National Academies Press.

Poduska, J., Gomez, M. J., Capo, Z., \& Holmes, V. (2012). Developing a collaboration with the Houston Independent School District: Testing the generalizability of a partnership model. Administration and Policy in Mental Health and Mental Health Services Research. doi:10.1007/s10488-011-0383-7.

Riemer, M., Kelley, S. D., Casey, S., \& Haynes, K. T. (2012). Developing effective research-practice partnerships for creating a culture of evidence-based decision making. Administration and Policy in Mental Health and Mental Health Services Research. doi:10.1007/s10488-011-0368-6.

Robertson, E. B., Sims, B. E., \& Reider, E. E. (2012). Partnerships in drug abuse prevention services research: Perspectives from the National Institute on Drug Abuse. Administration and Policy in Mental Health and Mental Health Services Research. doi: 10.1007/s10488-011-0400-x.

Rohrbach, L. A., Grana, R., Sussman, S., \& Valente, T. W. (2006). Type II translation: Transporting prevention interventions from research to real-world settings. Evaluation and the Health Professions, 29, 302-333.

Sandler, I. N., Knox, P., \& Braver, S. L. (2012). Collaboration of prevention science and the family court. Administration and Policy in Mental Health and Mental Health Services Research. doi:10.1007/s10488-011-0367-7.

Short, K. H., Weist, M.D., Manion, I. G., \& Evans, S. W. (2012). Tying together research and practice: Using ROPE for successful partnerships in school mental health. Administration and Policy in Mental Health and Mental Health Services Research. doi: 10.1007/s10488-011-0342-3.

Woolf, S. H. (2008). The meaning of translational research and why it matters. JAMA, 299, 211-213. 